\title{
Modelling the tongue-of-ionisation using CTIP with SuperDARN electric potential input: verification by radiotomography
}

\author{
S. E. Pryse ${ }^{1}$, E. L. Whittick ${ }^{1}$, A. D. Aylward ${ }^{2}$, H. R. Middleton ${ }^{1, *}$, D. S. Brown ${ }^{1}$, M. Lester ${ }^{3}$, and J. A. Secan ${ }^{4}$ \\ ${ }^{1}$ Institute of Mathematics and Physics, Aberystwyth University, Wales, UK \\ ${ }^{2}$ Department of Physics and Astronomy, University College London, UK \\ ${ }^{3}$ Department of Physics and Astronomy, University of Leicester, UK \\ ${ }^{4}$ NorthWest Research Associates, Inc., Tucson, USA \\ *now at: European Space Agency, European Space Astronomy Centre, Madrid, Spain
}

Received: 30 July 2008 - Revised: 13 January 2009 - Accepted: 27 January 2009 - Published: 6 March 2009

\begin{abstract}
Electric potential patterns obtained by the SuperDARN radar network are used as input to the Coupled Thermosphere-Ionosphere-Plasmasphere model, in an attempt to improve the modelling of the spatial distribution of the ionospheric plasma at high latitudes. Two case studies are considered, one under conditions of stable IMF $B_{z}$ negative and the other under stable IMF $B_{z}$ positive. The modelled plasma distributions are compared with sets of wellestablished tomographic reconstructions, which have been interpreted previously in multi-instrument studies. For IMF $B_{z}$ negative both the model and observations show a tongueof-ionisation on the nightside, with good agreement between the electron density and location of the tongue. Under $B_{z}$ positive, the SuperDARN input allows the model to reproduce a spatial plasma distribution akin to that observed. In this case plasma, unable to penetrate the polar cap boundary into the polar cap, is drawn by the convective flow in a tongue-of-ionisation around the periphery of the polar cap.
\end{abstract}

Keywords. Ionosphere (Modeling and forecasting; Plasma convection; Polar ionosphere)

\section{Introduction}

At polar and auroral latitudes the ionised atmosphere is a highly structured plasma, comprising electron density structures on a large range of horizontal spatial scale sizes. Of relevance to this study are features on scales of tens to hundreds of kilometres, which are reviewed by Crowley (1996). A

Correspondence to: S. E. Pryse (sep@aber.ac.uk) prominent example is the tongue-of-ionisation (TOI), where photoionisation from sub-auroral latitudes on the dayside is drawn antisunward by the high-latitude plasma convection pattern towards the polar cap (Valladares et al., 1994). At high F-region altitudes the lifetime of the plasma is sufficiently long for the ionisation to be drawn through the polar region and into the nightside sector. During its transit through the polar cap the TOI may be modulated into polar patches and various processes have been proposed for this (for example Anderson et al., 1988; Sojka et al., 1993; Rodger et al., 1994; Milan et al., 2002). A modelling study by Bowline et al. (1996) indicated that the TOI is expected to be prominent at Ny-Ålesund in the European sector in the evening under conditions of IMF $B_{y}$ negative, and observations of the remnants of the TOI and polar patches on the nightside in this sector are reported by Middleton et al. (2008) and Pryse et al. (2006).

Geophysical numerical models of the upper atmosphere such as the Coupled Thermosphere-IonospherePlasmasphere (CTIP) model (Fuller-Rowell et al., 1987) and the Utah State University time dependent ionospheric model (Sojka et al., 1981) have been used to model these persistent, large-scale features of the high-latitude ionosphere and to investigate the influence of the underlying physical processes on the plasma structuring. For example, Sojka et al. (1993, 1994) showed that the TOI can be modulated by season and UT and broken up into discrete patches by temporal changes in the plasma convection pattern due to variations in the IMF $B_{y}$. Early modelling work by Robinson et al. (1985) indicated that the evening side boundary blob may be formed by polar cap plasma drifting out of the polar cap and into the nightside sector where it is drawn into a latitudinally confined but longitudinally extended enhancement. 


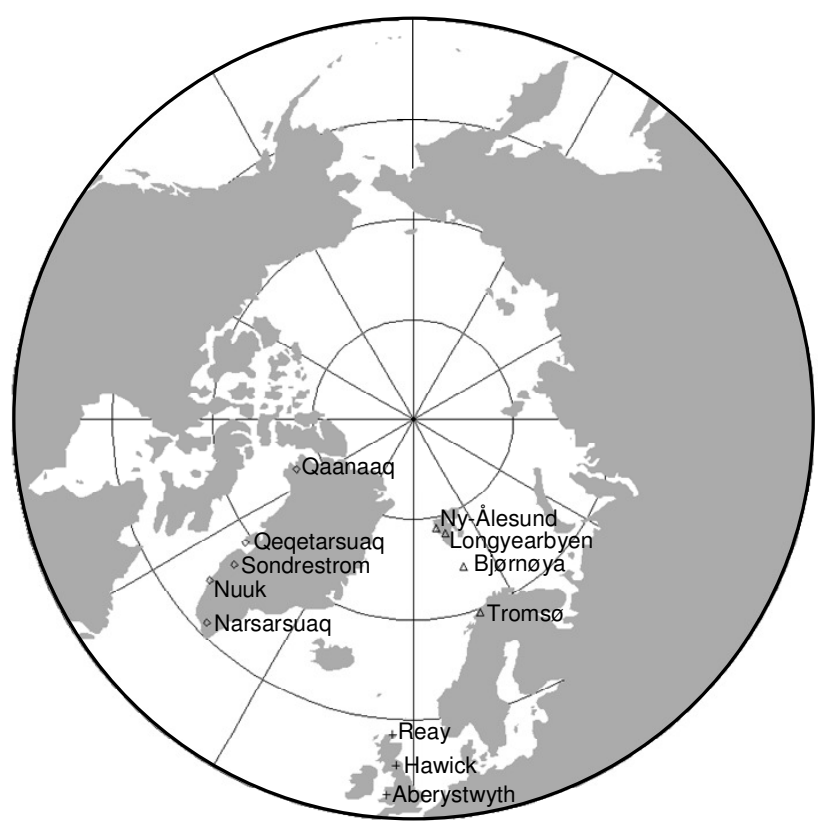

Fig. 1. Map showing the locations of the radio receivers of the tomography chains in Scandinavia, UK and Greenland.

These large-scale high-latitude ionisation enhancements have been observed by several experimental techniques including ionospheric sounders, radiotomography and incoherent scatter radar. However, there are very few direct comparisons of the ionospheric observations with modelled distributions. Middleton et al. (2008) presented multi-instrument observations of a cold high-altitude plasma enhancement on the nightside, interpreted as plasma produced on the dayside and transported across the polar cap in the convective flow into the auroral region. The interpretation was supported by model runs of the CTIP model, although there were disparities in the location and density levels of the observations and model output, with the modelled enhancement being a few degrees latitude equatorward of that observed and of generally slightly higher densities. Schoendorf et al. (1996) compared electron densities measured in the auroral region by the European incoherent scatter radar (EISCAT) with CTIP model output. This study also showed the potential of the model to reproduce the observed densities, but highlighted the important role of the high-latitude input parameters to the model to obtain broad agreement at all geographic locations and UTs.

There is a need to address disparities between observations and modelling arising from the high-latitude model drivers. One clear limitation of the CTIP model is the high-latitude electric potential pattern used as input. In previous studies this has been obtained from a library of patterns, classified according to geomagnetic conditions, and based on measurements by the Millstone Hill radar (Foster et al., 1986). Although it was the best that could be obtained at the time of implementation, the patterns do not necessarily provide good representation of a particular geophysical condition of interest, and are unable to provide suitable input for IMF $B_{z}$ positive when the convection includes lobe cells with sunward flow on the dayside (Cowley, 1998). The aim of this current study is to address the high-latitude convection input, by implementing electric potentials derived from observations by the Super Dual Auroral radar Network, SuperDARN (Greenwald et al., 1995; Chisham et al., 2007). No other alterations are made to the model, and it is stressed that no attempt is made to tweak the model to match observations.

Two particular case studies are considered, under contrasting IMF conditions. The first is under IMF $B_{z}$ negative with the SuperDARN radar revealing a classic two-cell convection pattern characteristic of the condition. The other is a case under IMF $B_{z}$ positive with the convection pattern likely to include polar lobe cells. The modelled output is compared with radiotomography observations made by the International Ionospheric Tomography Community (IITC), which give the latitudinal variation of the electron density on a spatial scale appropriate for comparison with the model output. The two case studies with different IMF orientations were chosen to coincide with well-studied radiotomography investigations. The tomography results have already formed the focus of two previous works into the physical processes operating at high latitudes (Middleton et al., 2005, 2008) where the observed features were interpreted by multi-instrument investigations. By choosing such cases, with mature interpretations of the data sets, ambiguity in the comparisons of observations with the model output was less likely.

\section{Model and experimental facilities}

\subsection{Coupled thermosphere-ionosphere-plasmasphere model}

The Coupled Thermosphere-Ionosphere-Plasmasphere (CTIP) model provides a powerful tool for investigating the roles of the various physical processes in the thermosphere, ionosphere and plasmasphere and the interplay between them. At high latitudes the ionosphere is influenced to varying degrees by solar EUV radiation, precipitation of charged energetic particles, electrodynamic fields and drifts, diffusion, thermospheric winds and temperature-sensitive chemical reactions. The early development of the coupled model at University College London and The University of Sheffield, covered the thermospheric model (Fuller-Rowell and Rees, 1980, 1983) and its integration with models of the high-latitude ionosphere (Quegan et al., 1982) and the plasmasphere (Millward et al., 1996). In brief, the CTIP model solves coupled equations of momentum, energy and continuity at fixed grid points to calculate the density, temperature and velocity of the neutral atmosphere, and of the $\mathrm{O}^{+}$and $\mathrm{H}^{+}$ions on closed flux tubes in the plasmasphere 


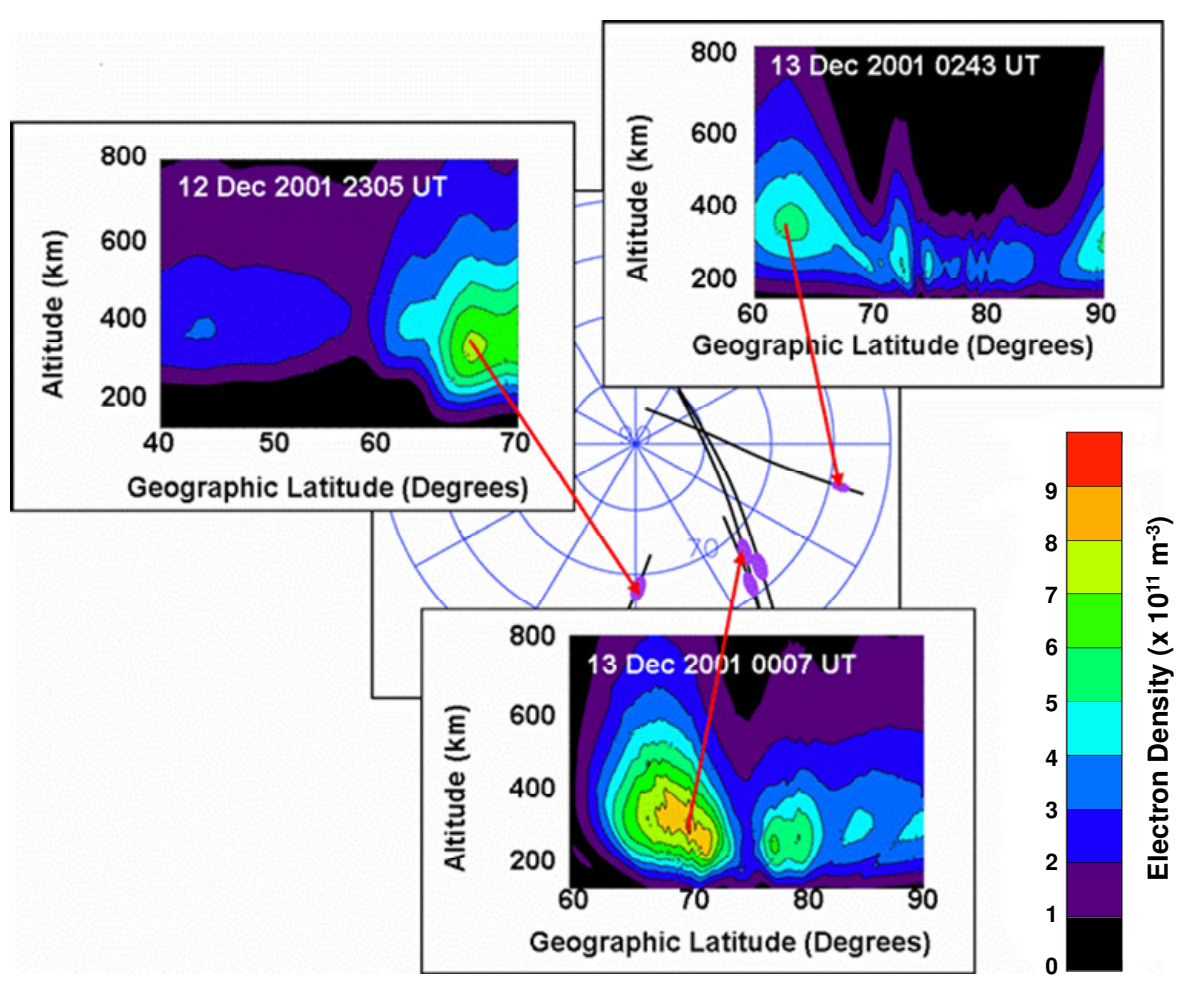

Fig. 2. Three sample tomography reconstructions for 23:05 UT (UK), 00:07 UT (Scandinavia) and 02:43 UT (Scandinavia) on the evening of 12-13 December 2001. The locations of the maximum electron density of the prominent enhancement in the three reconstructions, and two other reconstructions (not shown), are indicated in the centre panel by the purple dots on a MLAT versus MLT polar plot. Magnetic local midnight is at the bottom of the circles, with 06:00 UT on the right-hand-side.

and open flux tubes at high latitudes (Fuller-Rowell et al., 1987). The output quantities are determined on a geocentric grid with a resolution of $2^{\circ}$ latitude, $18^{\circ}$ longitude and one scale height from a lower boundary fixed at $80 \mathrm{~km}$ at $1 \mathrm{~Pa}$.

Since the early development of the coupled model, various adaptations have been carried out at The University of Sheffield, University College London and the Space Environment Laboratory, USA. The model used in the current study is a modified version of the Sheffield CTIP model. Its general input drivers are the day number, the solar flux F10.7 index, the $K_{p}$ index that sets the level of auroral precipitation, and a selected high-latitude electric potential pattern normally chosen from the library of patterns based on measurements by the Millstone Hill radar. The output parameter of interest is the ion density of the F-region ionosphere, given at hourly intervals of UT.

For the model runs presented in this paper, the day number and solar flux F10.7 index were set in accord with the time of observations. The auroral precipitation input was switched off for the main study, so as to focus on effects of the transport of plasma at polar and auroral latitudes. Of particular interest was the electric potential pattern input, where the library input was substituted by an electric potential pattern from the SuperDARN radar network (Sect. 2.2). This pattern was selected to be appropriate for the time of the tomography observations and obtained from the SuperDARN website (http://superdarn.jhuapl.edu/).

\subsection{Super Dual Auroral Radar Network}

The Super Dual Auroral Radar Network, SuperDARN, (Greenwald et al., 1995; Chisham et al., 2007) currently comprises fourteen coherent scatter radars at high latitudes in the Northern Hemisphere and seven in the Southern Hemisphere. Of relevance to this study are measurements of the line-ofsight velocity of F-region convection flows made by nine of the Northern Hemisphere radars. These are inverted using the spherical harmonic fitting technique described by Ruohoniemi and Baker (1998) to shape modelled electric potentials to produce maps of the ionospheric high-latitude electric potential. The electric potentials for the Northern Hemisphere were then used as input to the CTIP model in the current investigation.

\subsection{Radiotomography}

Each of the radiotomography experiments used for the study comprised a chain of radio receivers separated in latitude but essentially aligned in longitude. Phase coherent signals 


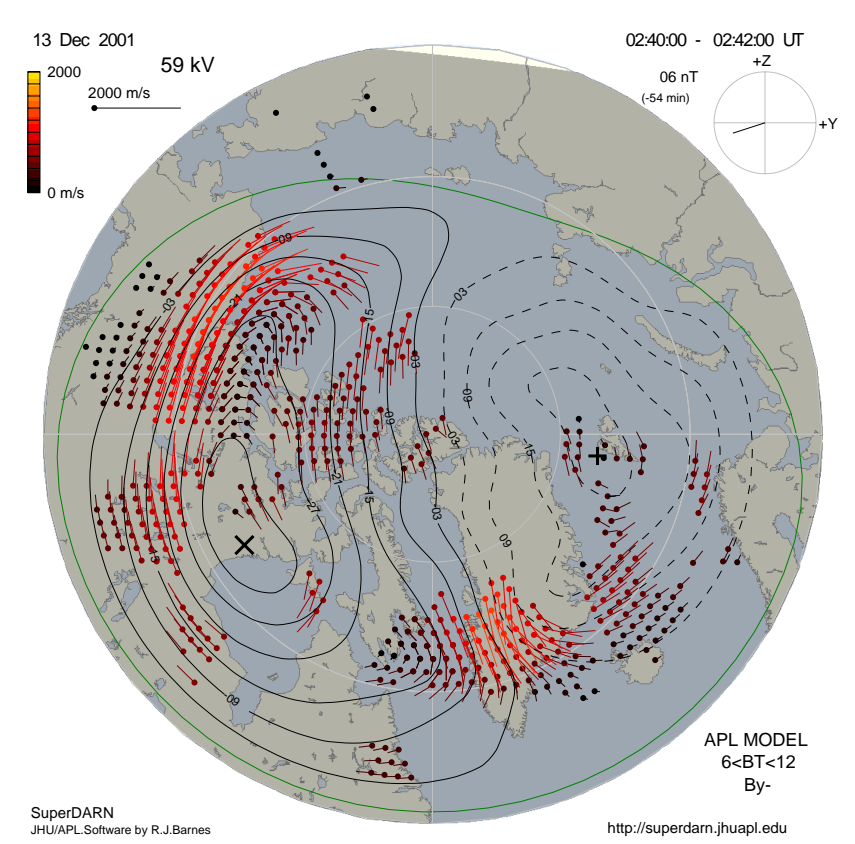

Fig. 3. Contours of the SuperDARN electric potential pattern for 02:40 UT on 13 December 2001. The short lines indicate the ionospheric drift velocities measured by the radars with their lengths and colours representing the drift magnitude and their orientations indicating the direction of flow.

at $150 \mathrm{MHz}$ and $400 \mathrm{MHz}$ from the polar orbiting satellites of the Navy Ionospheric Monitoring System (NIMS) were monitored at each receiver during a satellite pass to measure total electron contents along a large number of intersecting satellite-to-receiver ray paths. The collective set of electron content observations obtained during the pass were inverted using a tomography technique to yield the spatial distribution of electron density in a height-versus-latitude plane through the ionosphere (Pryse, 2003, and references therein). Tomographic reconstructions from three chains of the International Ionospheric Tomography Community (ITC) were used: two operated by Aberystwyth University in the Scandinavian sector and the UK, and the third in Greenland operated by the Applied Research Laboratories, University of Texas. The locations of the receivers in the three chains are shown in Fig. 1.

\section{Results}

\subsection{IMF $B_{z}$ negative: 12-13 December 2001}

\subsubsection{Experimental observations}

The period of interest spanned an interval from about 23:00 UT on 12 December 2001 to 03:00 UT on 13 December 2001. The $B_{z}$ component of the IMF governing the highlatitude plasma flow had been negative at about $-5 \mathrm{nT}$ for more than $10 \mathrm{~h}$ prior to the time interval and remained likewise for the period of observations. The IMF $B_{y}$ component was also stable throughout, with values between approximately $-6 \mathrm{nT}$ and $-2 \mathrm{nT}$. Inspection of the online SuperDARN electric potential patterns at $10 \mathrm{~min}$ intervals showed the characteristic two-cell pattern, consistent with antisunward plasma flow over the polar cap from the day to the nightside and return sunward flows at lower latitudes on the dawn and dusk flanks. The electric potentials showed the inevitable small variations in the detail of the cells from frameto-frame, but on the large scale their general form remained essentially unchanged throughout the time interval with the dawn cell being slightly smaller than the dusk cell. Tomographic reconstructions from five satellite passes during the interval, three monitored by the Scandinavian chain and two by the chain in the UK, showed a clear, persistent density enhancement that formed the poleward wall of the main ionisation trough in the post-magnetic midnight local time sector. Figure 2 shows three of the reconstructions as examples, two obtained from the Scandinavian chain and the other from the UK chain. The locations of the maximum density of the enhancement in all five reconstructions are also shown mapped onto a magnetic latitude (MLAT) versus magnetic local time (MLT) polar plot. Comparisons of the tomographic observations with measurements by the EISCAT UHF radar at Troms $\varnothing$ on mainland Norway showed that the enhanced densities were cold and at high altitudes, and supported the interpretation of the features being cross-sections through ionisation that had originated at an earlier time and different location, possibly on the dayside, and had been carried by the plasma flow in a tongue-of-ionisation into the region of observations. Further details of the observational results and their interpretation are given by Middleton et al. (2008).

\subsubsection{CTIP model output}

The model was run for 13 December and an F10.7 index of 230. SuperDARN electric potentials for 02:40 UT were taken to be representative of the interval, and showed clearly the two-cell pattern with the dawn cell being slightly smaller than the dusk cell (Fig. 3). The model was allowed to attain steady-state for both the thermosphere and ionised atmosphere. The ion density output from the model at an altitude of $320 \mathrm{~km}$, near the peak of the modelled nighttime F-region, is shown at 3-hourly intervals of UT in the polar plots of Fig. 4. Magnetic noon is at the top of each panel, with 18:00 MLT on the left-hand-side and 06:00 MLT on the right-hand-side. Magnetic latitude extends from $50^{\circ}$ MLAT on the outer circumference to the magnetic pole at the centre. The small white region near the pole encompasses the geographic pole, a region where this version of the model is unable to produce reliable output due to the convergence of the lines of longitude. A prominent plasma feature in most of the panels is the tongue-of-ionisation (TOI) comprising photoionisation drawn from the dayside into the nightside 
13 Dec 2001
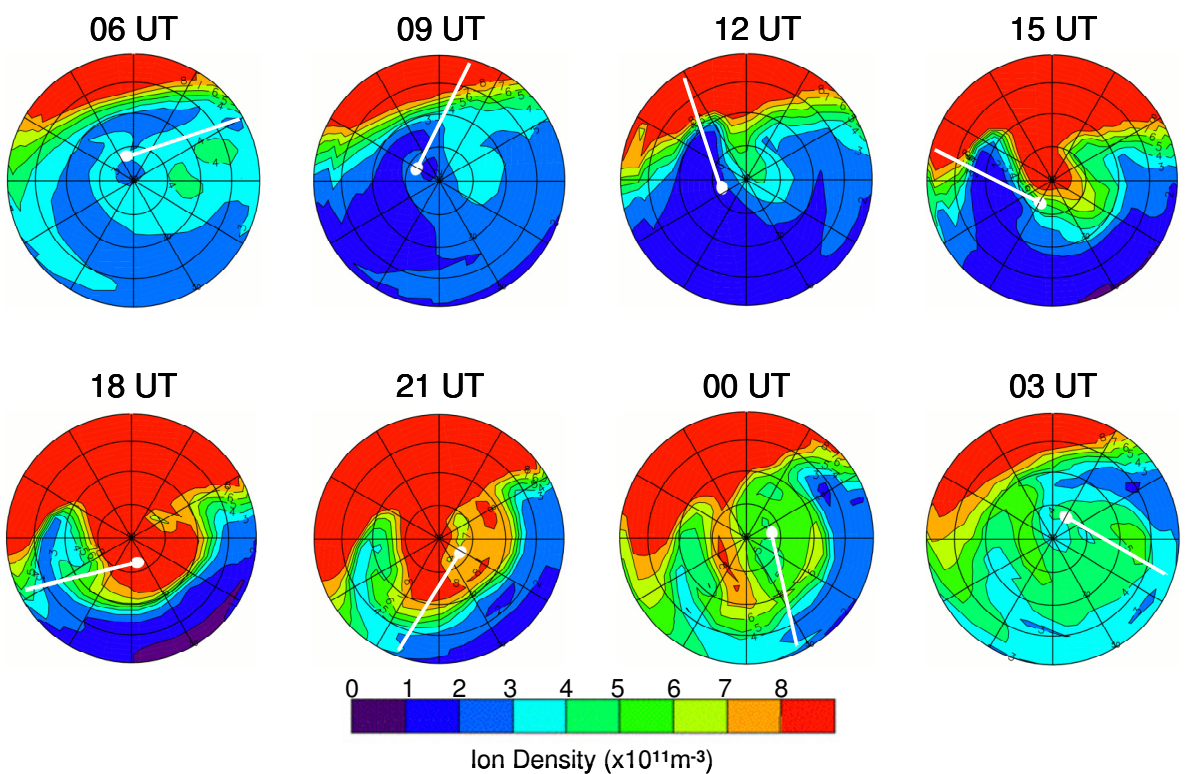

Fig. 4. Ion densities modelled by CTIP for 13 December 2001. The panels are at 3-h intervals of UT, with each panel showing the ion density distribution at an altitude of $320 \mathrm{~km}$, near the F-region ionisation peak, as a function of MLAT and MLT. Magnetic latitude extends from $50^{\circ}$ MLAT at the outer circumference to the magnetic pole in the centre of the circle. Magnetic noon is at the top of each panel with midnight at the bottom, 18:00 MLT is on the left-hand side and 06:00 MLT on the right-hand side. The small white region near the centre encompasses the geographic pole, and the white line shows the $18^{\circ} \mathrm{E}$ meridian near the longitude of the Scandinavian tomography chain.

post-midnight sector by the convective flow. A UT dependency is clear in the TOI, with the feature being most prominent in the 18:00 UT panel but with only remnants visible at 06:00 UT. This variation is attributed to the offset of the geomagnetic and geographic reference systems, with a larger proportion of the magnetically controlled convective flow being in sunlight when the geomagnetic pole is closer to the Sun than the geographic pole, for example near 18:00 UT. The white line shows the locus of the $18^{\circ} \mathrm{E}$ meridian, near the location of the Scandinavian receiver chain. The interception of the tongue by this line in the bottom panels suggests that the European sector is well-located to observe the effects of the tongue on the nightside.

Figure 5 shows the ion density output in the same format as Fig. 4 but at hourly intervals spanning the time of interest for the study. The panels for 22:00 UT and 23:00 UT are strictly for a model run for 13 December rather than for 12 December, the day the pre-midnight tomography observations were made, however this is not of significance as there is very little variation in the model output from day-to-day near the winter solstice when all other conditions are kept identical. A TOI is prominent in the panels for the earlier times, being drawn over the polar region into the nightside and then towards the dawn sector at auroral latitudes. The $300 \mathrm{~km}$ intersections of the satellite trajectories for each of the five tomography reconstructions are shown on the respective panels. Those for the two reconstructions at 01:50 UT
(UK chain) and 01:56 UT (Scandinavian chain) are for the same satellite pass, but are shown on different model panels for clarity.

\subsubsection{Comparison between model output and radioto- mography observations}

Comparisons of the modelled output and the tomography reconstructions are shown in the two panels of Fig. 6. The top row of each panel shows the latitude-versus-altitude modelled distributions given at $18^{\circ} \mathrm{E}$ for hourly intervals covering 22:00 UT to 03:00 UT, where the main feature in each of the plots is the intersection through the TOI drawn into the dusk side. The colour scale used for the latitude-versusaltitude plots are slightly different from those of the polar plots to allow direct comparison with the tomography reconstructions. The density of the TOI intersection decreases with UT as a consequence of ionisation recombination in winter darkness, and its latitude decreases as it is drawn further towards dawn by the convective flow. The second row of each panel shows the corresponding tomography images. Owing to the difference in the latitude coverage of the UK and Scandinavian reconstructions, the images have been offset accordingly to ensure consistency in the latitudinal location of the enhancement. The large density enhancement forming the poleward wall of the main ionisation trough is a prominent feature of each reconstruction. The smaller-scale density 


\section{Dec 2001}
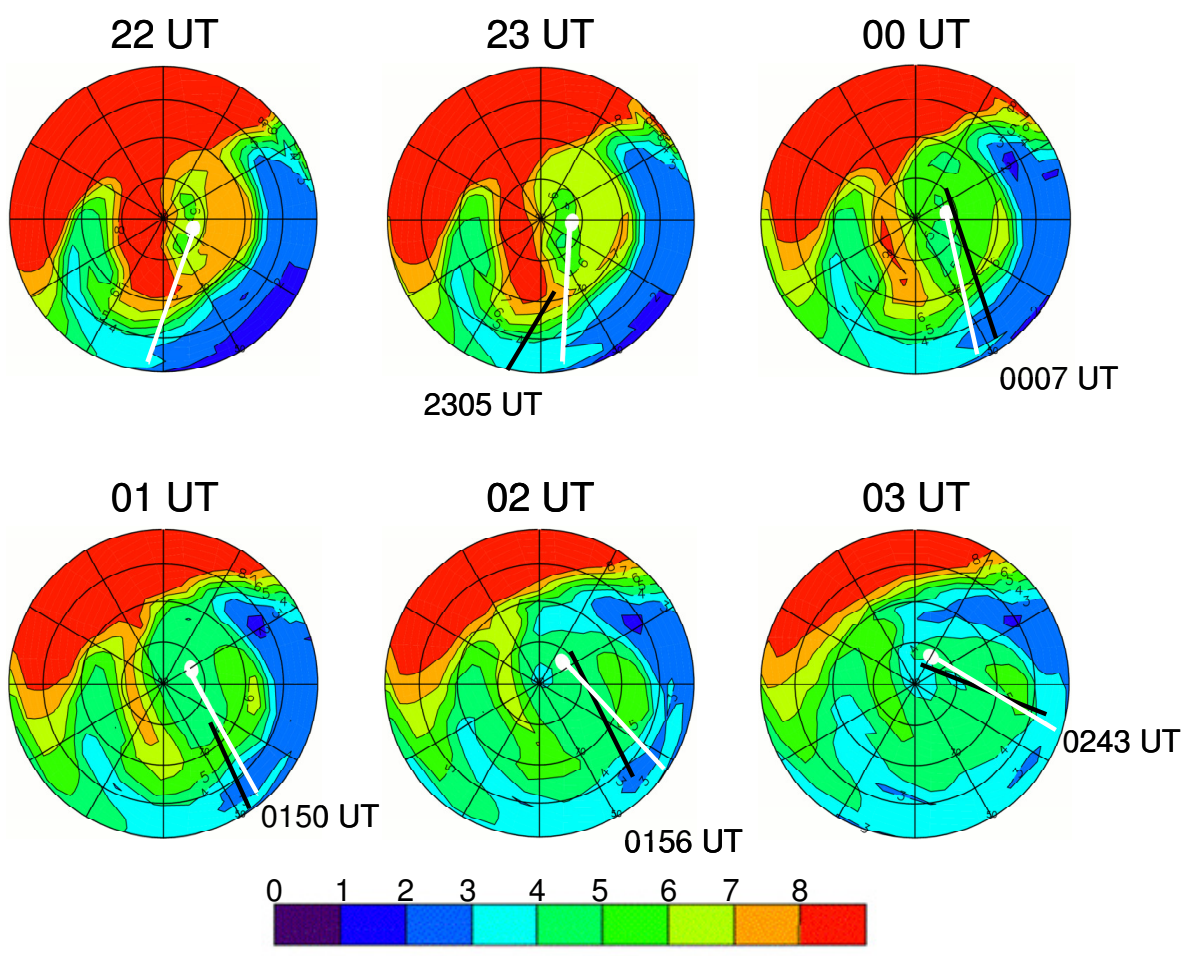

Ion Density $\left(\times 10^{11} \mathrm{~m}^{-3}\right)$

Fig. 5. Ion densities modelled by CTIP from 22:00 UT to 03:00 UT for 13 December 2001. The panels are at hourly intervals of UT, with each panel showing the ion density distribution at an altitude of $320 \mathrm{~km}$, near the F-region ionisation peak, as a function of MLAT and MLT. The format of the panels is the same as for Fig. 4, with the white line showing the $18^{\circ} \mathrm{E}$ meridian near the longitude of the Scandinavian tomography chain. The black lines indicate the $300 \mathrm{~km}$ trajectory intersections of the satellite passes of the reconstructions.

features seen poleward of the large enhancement and generally at lower altitude in the images from Scandinavia are likely to be in the auroral region, and caused by soft particle precipitation. However, these smaller structures are outside the scope of the current study and will not be considered further. The discontinuity in the equatorward field of view of the reconstruction at 01:56 UT occurs because of the satellite signal being lost at this location, and the image to the left of the discontinuity reverts to the initial background ionosphere for the inversion process. In general, the observed densities in the large enhancement are in good agreement with those modelled. A general trend of decreasing densities with increasing UT for the enhancement is revealed in the observations, as in the modelling, although there are some slight deviations in the trend, in particular an increase in the reconstruction at 00:07 UT. Possible reasons for this deviation are small temporal variations in the convection or particle precipitation upstream at an earlier time, which would not be taken into account in the CTIP model. The locations of the modelled and observed enhancement are in reasonable agreement. For example, in the model panel for 00:00 UT and tomography reconstruction at 00:07 UT, the maximum density is near $70^{\circ} \mathrm{N}$ and $69^{\circ} \mathrm{N}$ for the model and observations, re- spectively. The observed equatorward and poleward edges of the enhancement as defined by the $5 \times 10^{11} \mathrm{~m}^{-3}$ contour are at $64^{\circ} \mathrm{N}$ and $74^{\circ} \mathrm{N}$, respectively, while the corresponding equatorward edge in the model is also at $64^{\circ} \mathrm{N}$ but the northern most edge is at almost $80^{\circ} \mathrm{N}$. Similarly, the extremes of the enhancement on the right-hand-side of the bottom panel are at $62^{\circ} \mathrm{N}$ and $65^{\circ} \mathrm{N}$ in the reconstruction at 02:43 UT and $63^{\circ} \mathrm{N}$ and $67^{\circ} \mathrm{N}$ for the model at 03:00 UT. In both examples the modelled enhancement extends over a larger latitude range than that observed, with a tendency for the latitudinal gradients of the modelled walls to be less steep than those observed. The difference in gradient is a likely consequence of the different latitudinal spatial resolutions of the model and observations, with the latitudinal dimension of the pixels being $0.25^{\circ}$ in the tomography reconstruction but $2^{\circ}$ in the model. There are also differences in the vertical profiles of the observations and model, however, since there is some ambiguity in the vertical distribution of tomographic images, arising due to a limited observing geometry (Pryse, 2003), it is not possible to draw definitive conclusions here.

Energy deposition by particle precipitation has been excluded from the main study, with the auroral input in general being switched off in the model runs. However, output 

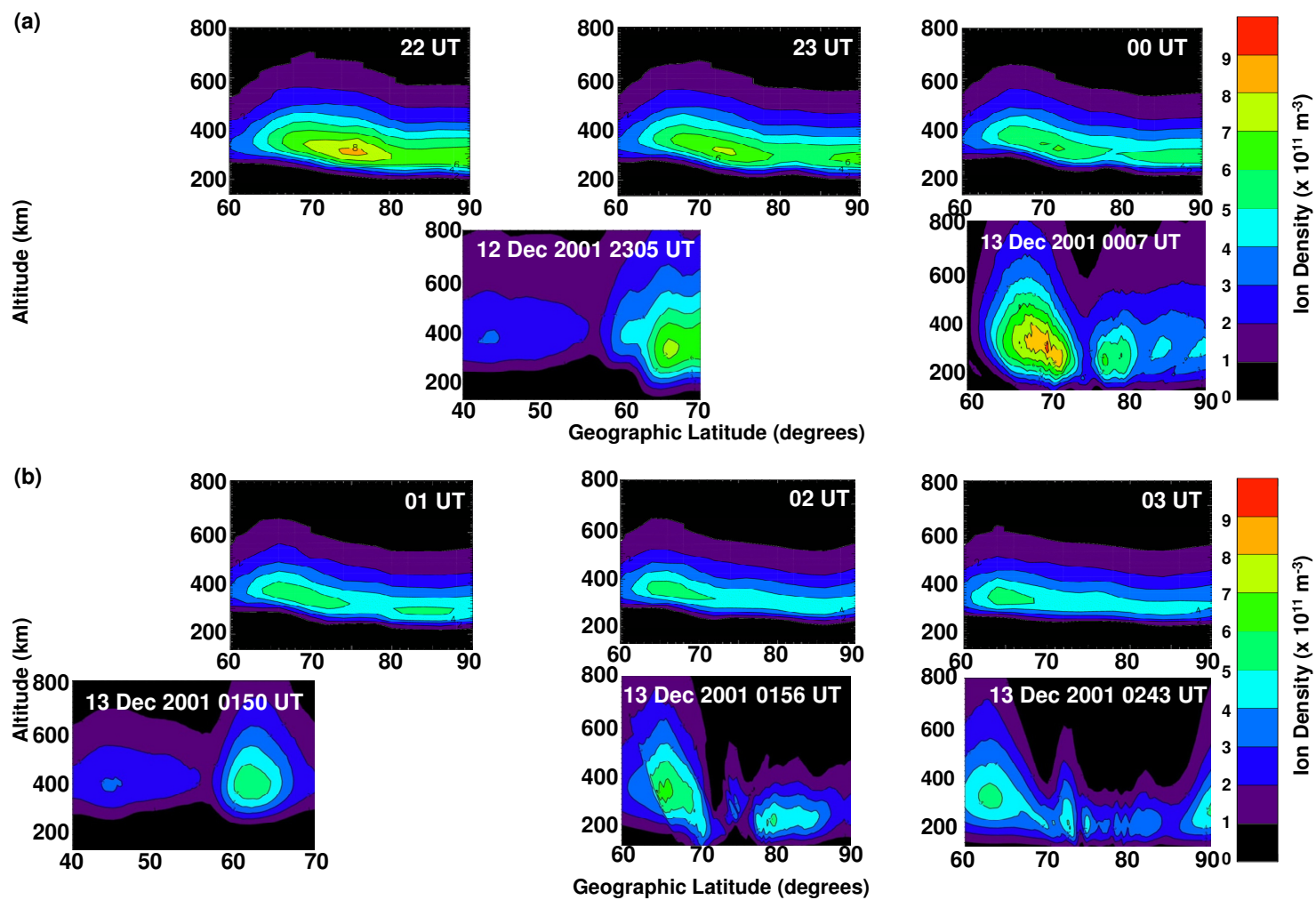

Fig. 6. Comparison of the CTIP modelled ion density (top row of each panel) and radiotomography observations (bottom row of each panel) on a latitude-versus-altitude grid. The modelled densities are at the $18^{\circ} \mathrm{E}$ meridian at hourly intervals between 22:00 UT and 00:00 UT in panel (a) and between 01:00 UT and 03:00 UT in panel (b). These are paired with the corresponding tomography images in the bottom row of each panel. The reconstructions from the UK tomography chain are displaced to the left of those for the Scandinavian chain for consistency in the latitudinal placement of the observed ionisation enhancement.

from a run corresponding to that in Fig. 4, but with the precipitation switched on and with a $K_{p}$ index of 2 appropriate for 00:00-03:00 UT on 13 December, is shown in Fig. 7. The first panel for 06:00 UT, when the TOI is absent, shows the effect of the precipitation with a partial ring of enhanced ionisation representing the auroral oval. This reaches a latitude of about $80^{\circ} \mathrm{MLT}$ near noontime but extends to lower latitudes on the nightside. Comparison with the corresponding panel in Fig. 4 reveals that the density level in the auroral postmagnetic midnight sector is increased from about $2-4 \times 10^{11} \mathrm{~m}^{-3}$ to about $5-7 \times 10^{11} \mathrm{~m}^{-3}$ when precipitation is included. Increased density levels also occur in regions removed from the immediate region of the auroral precipitation, with values in the region of smallest nightside density increasing from $2-3 \times 10^{11} \mathrm{~m}^{-3}$ to $3-4 \times 10^{11} \mathrm{~m}^{-3}$. Care is needed in the interpretation of the colour scales in the comparisons, as the highest red level has been increased from greater than $8 \times 10^{11} \mathrm{~m}^{-3}$ to greater than $9 \times 10^{11} \mathrm{~m}^{-3}$ in the precipitation model output in order to clearly show the features of interest. The TOI remains a dominant feature of the panels of 12:00 UT to 00:00 UT (Fig. 7), maximising at 18:00 UT to 21:00 UT. The densities in the tongue are en- hanced by the precipitation, for example the maximum density at 00:00 UT in the absence of precipitation was some $6-7 \times 10^{11} \mathrm{~m}^{-3}$, whilst with precipitation it is in excess of $8 \times 10^{11} \mathrm{~m}^{-3}$ and more in line with those in the enhancement observed at 00:07 UT. Fuller treatment of the precipitation is outside the scope of this investigation. However, it has a marked effect that needs consideration in future as indicated by Schoendorf et al. (1996) and Pryse et al. (2005).

\subsection{IMF $B_{z}$ positive: 26 November 2001}

\subsubsection{Experimental observations}

The IMF $B_{z}$ and $B_{y}$ components were very stable between about 11:00 UT and 16:00 UT on 26 November 2001. $B_{z}$ was positive with values essentially between $0 \mathrm{nT}$ and $1 \mathrm{nT}$ and $B_{y}$ was between about $-3 \mathrm{nT}$ and $-1 \mathrm{nT}$. During the interval six satellite passes were monitored by the Scandinavian chain and six by the chain in Greenland displaced by some $70^{\circ}$ longitude to the west. Collectively, the reconstructions showed a stable ionosphere with spatial rather than temporal variation. The images showed evidence of a localised density 


\section{Dec 2001 - With Precipitation}
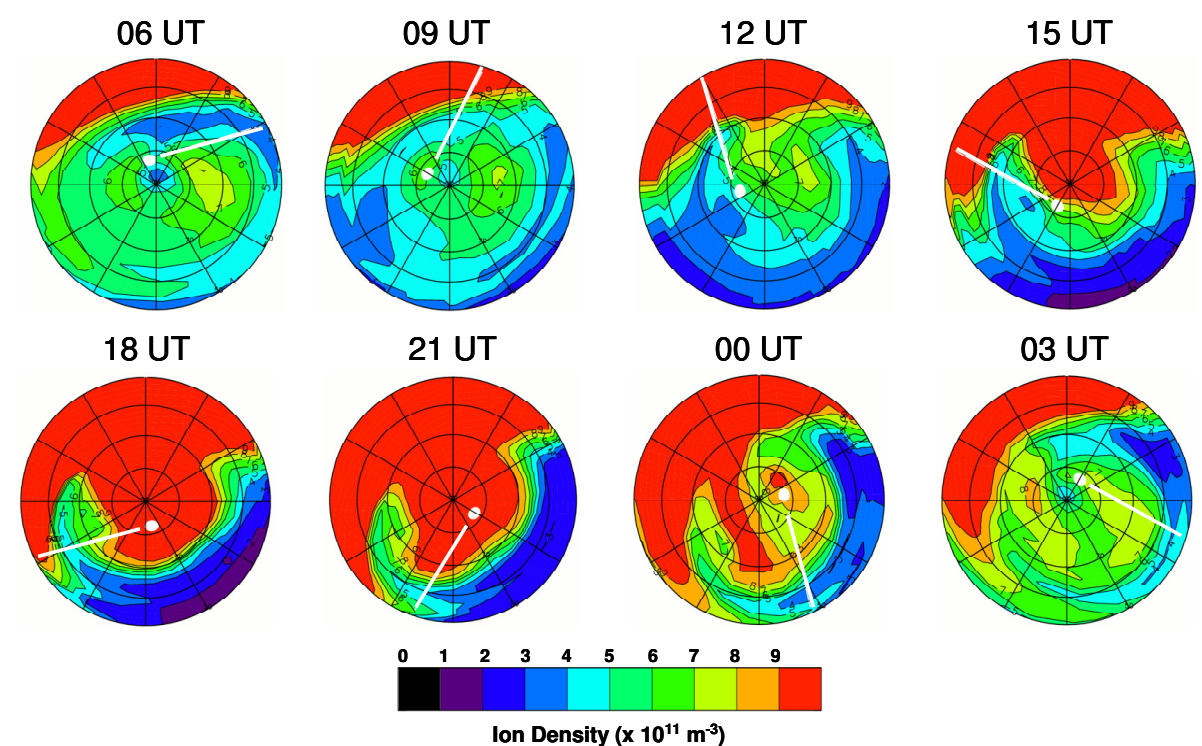

Fig. 7. Ion densities modelled by CTIP for 13 December 2001, but with precipitation input included in the model. The panels are at 3-h intervals of UT, with each panel showing the ion density distribution at an altitude of $320 \mathrm{~km}$, near the nightside F-region ionisation peak, as a function of MLAT and MLT. The format of the panels is as for Fig. 4, with the white line showing the $18^{\circ}$ E meridian near the longitude of the Scandinavian tomography chain.

enhancement poleward and distinct from the main photoionisation. Figure 8 shows the trajectories of all twelve passes, which were essentially in the 12:00-18:00 MLT time sector. A dot on each trajectory, with the exception of the two trajectories nearest to 12:00 MLT where the features were not clearly distinct, indicates the location of the maximum electron density of the localised enhancement observed during the pass. Three sample tomography reconstructions are also shown, showing the enhancement apparently becoming increasingly detached from the photoionisation with increasing MLT. The full set of reconstructions was presented and interpreted by Middleton et al. (2005) with the enhanced densities being identified as cross-sections through a TOI (shown schematically by the purple curve in Fig. 9) drawn antisunward around the periphery of a polar cap closed to plasma inflow under the condition of northward IMF. The interpretation was supported by satellite horizontal cross-track plasma drift measurements.

\subsubsection{CTIP model output}

The CTIP model was run for 26 November 2001 with an F10.7 value of 175 , appropriate for the day but significantly lower than in the previous study. There were only limited plasma drift measurements by the SuperDARN radar for this particular interval, which lacked the large scale coverage required to shape the electric potential patterns. In consequence SuperDARN electric potentials from another time were used. The example chosen was for 01:30 UT on 18 De- cember 2002 (Fig. 10), where the flow measurements were plentiful and revealed a sunward flow on lobe cells in the polar cap. This pattern was chosen because its general form was broadly similar to that inferred from DMSP cross-track observation shown in Middleton et al. (2005), comprising sunward flow on the dayside near 12:00 MLT, and antisunward flow at lower latitudes on both the dawn and dusk sides. However, given the general variations between plasma convection patterns there were inevitably differences in detail. The IMF $B_{z}$ influencing the chosen SuperDARN pattern was also positive and stable, but with values between about $8 \mathrm{nT}$ and $9 \mathrm{nT}$, significantly larger than those corresponding to the tomographic images. At this stage no attempt was made to compare the chosen electric potential pattern directly with the tomographic observations.

The modelled ion densities at 3-hourly UT intervals are shown in Fig. 11. The panels take the same format as those in Fig. 4, but are for an altitude of $270 \mathrm{~km}$ which was more appropriate for the height of the F-region peak in this instance. The white line shows the $18^{\circ} \mathrm{E}$ meridian near the Scandinavian chain and the black line the $54^{\circ} \mathrm{W}$ meridian near the chain in Greenland. The modelled densities are substantially less than those for the $B_{z}$ negative case, attributed to the lower F10.7 index value. The variation of dayside photoionisation with UT is again clearly seen, but in this case there is no TOI over the central polar cap. Careful inspection reveals two less intense TOIs drawn antisunward between about $70^{\circ}$ MLAT and $80^{\circ}$ MLAT in the panels centred on a 


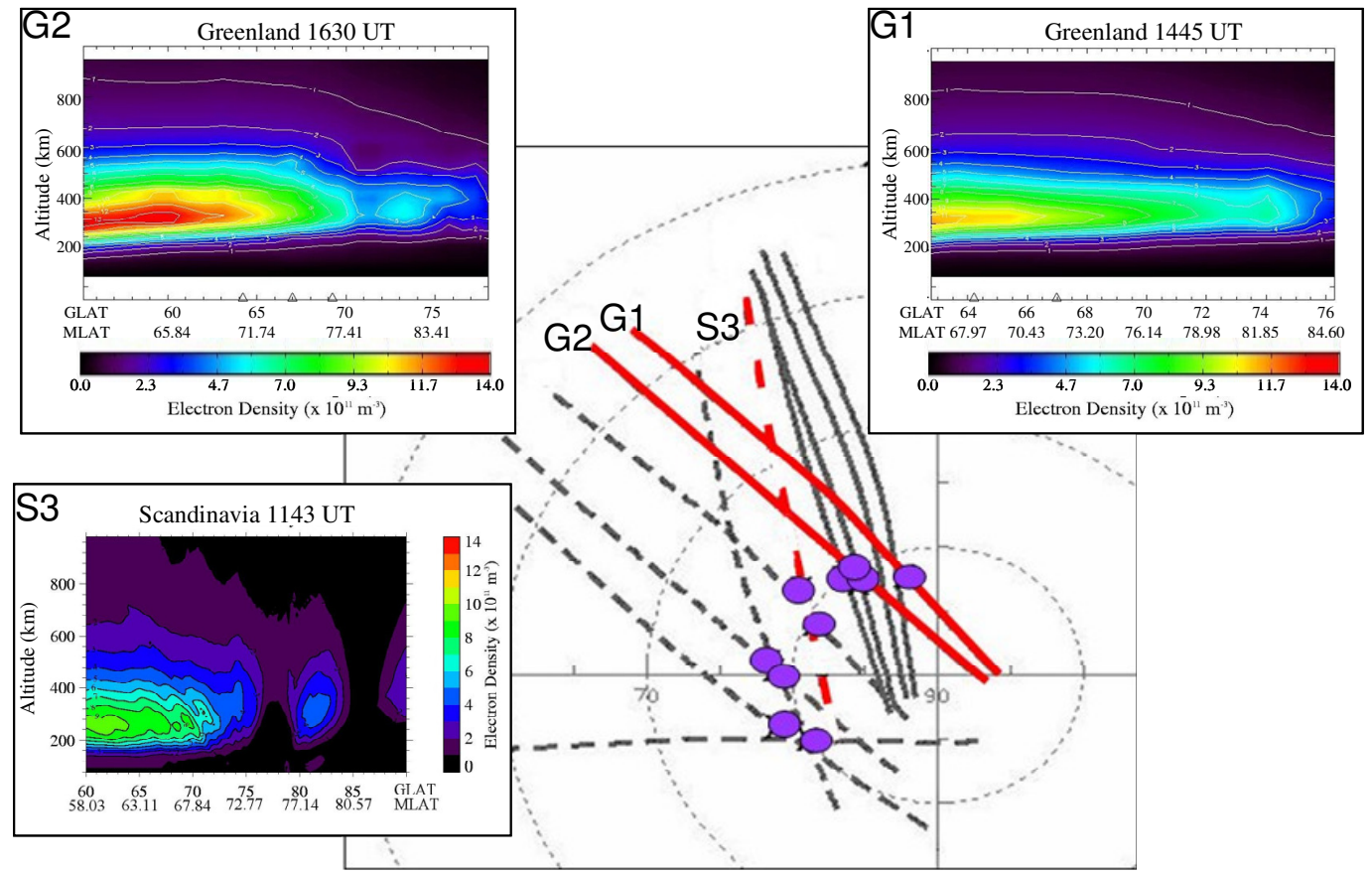

Fig. 8. Three sample tomography reconstructions for 14:45 UT (Greenland), 16:30 UT (Greenland) and 11:43 UT (Scandinavia) on 26 November 2001. The trajectories of the corresponding three satellite passes are shown in red in the centre panel on a MLAT versus MLT polar plot. The locations of the electron density feature detaching from the main photoionisation for these reconstructions and another seven reconstructions (not shown) are indicated by the purple dots in the centre panel.

universal time of 18:00 UT, one on the afternoon side and the other on the dawn side. A hint of the features can be seen in the panel for 12:00 UT and remnants at 00:00 UT, but it is absent in the panels for 03:00 UT, 06:00 UT and 09:00 UT.

Corresponding model outputs at hourly intervals between 11:00 UT and 18:00 UT are shown in Fig. 12, encompassing the time of interest. The sequence shows the growth phase of the TOIs, with the white line at the $18^{\circ} \mathrm{E}$ meridian intersecting the afternoon tongue. At the later UTs the line has almost "overtaken" the TOI and intersects the lower densities at its nose. The $54^{\circ} \mathrm{W}$ meridian shown by the black line lags the $18^{\circ} \mathrm{E}$ through the early stages of the development of the afternoon tongue. The satellite trajectories, indicated in MLT in Fig. 8, were broadly in the vicinities of the two meridians shown in Fig. 12.

\subsubsection{Comparison between model output and radioto- mography observations}

Latitude-versus-altitude intersections through the model output at $18^{\circ} \mathrm{E}$ (Fig. 13) clearly show the TOI starting to separate from the main photoionisation at 13:00 UT and becoming increasingly distinct with increasing UT. A high-latitude afternoon trough develops in-between the two enhancements as the coverage of photoionisation to the high latitudes is reduced with increasing MLT, and this ionisation becomes increasingly separated from the TOI. By 16:00 UT the two

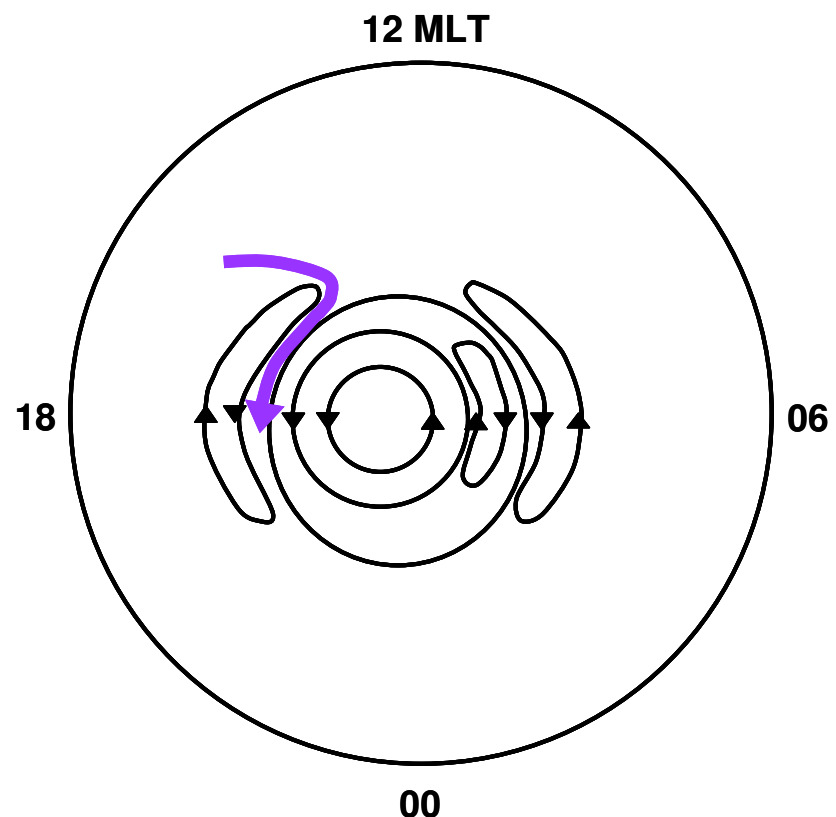

Fig. 9. Schematic showing the TOI being drawn around the periphery of the polar cap under conditions of IMF $B_{z}$ positive. The purple curve indicates the TOI, and the streamlines are representative of the plasma convective flow under the pertinent IMF conditions. 


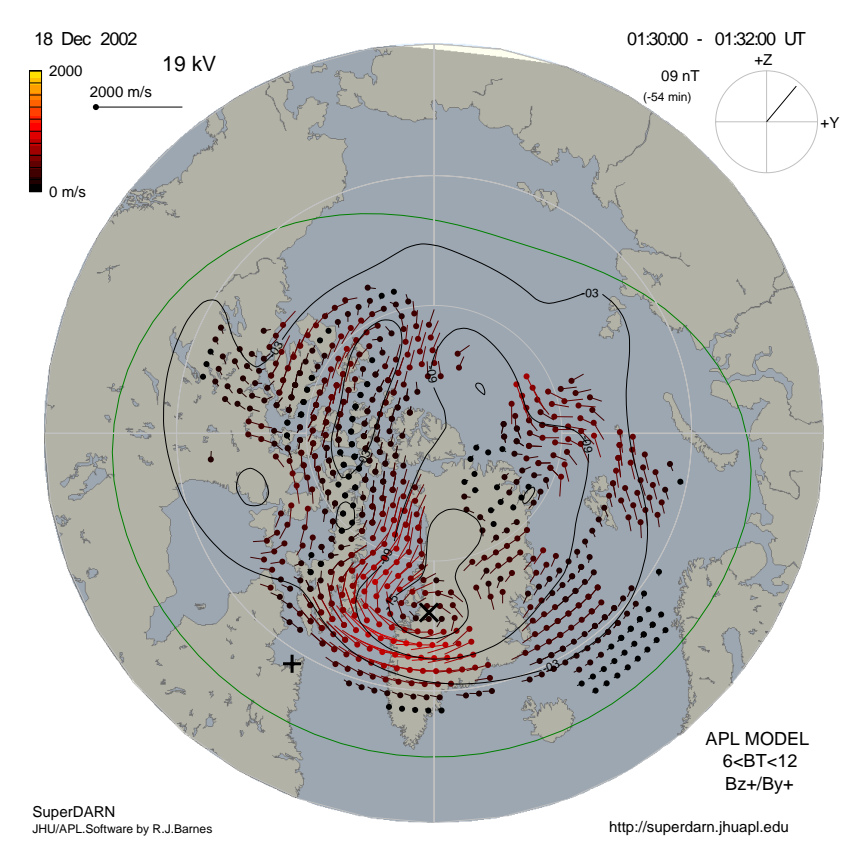

Fig. 10. Contours of the SuperDARN electric potential pattern for 01:30 UT on 18 December 2002, showing sunward flow across the polar cap. The short lines indicate the magnitude and direction of the ionospheric drift velocities measured by the radars.

regions of larger densities are completely separated on the contouring scale used.

It is not appropriate to make a one-to-one comparison between the details of the model and tomography images in this case as was done in the previous case study, owing to the electric potential pattern not corresponding directly to the time of observations. However, the similarities of the observed and modelled plasma distributions are clearly seen, with both the panels of Fig. 13 and the three tomography reconstructions in Fig. 8 showing a TOI near $70^{\circ}-80^{\circ}$ MLAT separating from the main photoionisation as UT and MLT increase. Decreasing density levels with increasing time also occur in both model and observations, attributed to ionisation recombination in the absence of sunlight. Despite differences in the finer details, such as in the absolute density levels, the comparison shows the capability of the CTIP model to reproduce the spatial structure of the polar cap ionisation distribution under steady IMF $B_{z}$ positive.

\section{Discussion}

The large-scale spatial structure of the polar and auroral ionosphere is governed strongly at high latitudes by the electric potentials. The underlying physics is relatively well understood, however the variability that the electric potentials demonstrate because of solar wind and magnetospheric influences remains to be addressed. It is not possible at present to predict the detail of the size and strength of the electric poten- tial pattern at any given time. The CTIP model uses the electric potentials as an input driver. A limitation of the model has been the restricted set of electric potential patterns available to describe the horizontal transport of plasma within the polar and auroral regions, with those available being provided from a library of potential patterns. The set comprises patterns of various sizes and strength, but generally with a two-cell configuration. It does not contain patterns that include sunward lobe-cell flow within the polar cap as is often the case under IMF $B_{z}$ positive. An unsuitable electric potential input for a given situation leads to significant limitations in the ability of the CTIP model to predict the plasma distribution. The current study addresses this shortcoming by using electric potentials obtained from the SuperDARN radar that are readily available from the SuperDARN website. Whilst it is appreciated that second level SuperDARN data is available on request, this was not deemed necessary for the proof-of-concept study where the IMF conditions and electric potentials were stable over an extended period of time. Use of the on-line potentials was also regarded as moving towards "near-real-time" modelling and prediction of the ionosphere.

Radiotomography imaging, with an extended latitudinal coverage and a latitudinal pixel dimension of $0.25^{\circ}$ for the reconstruction grid, is particularly well suited for verification of the CTIP model which has a latitudinal step dimension of $2^{\circ}$ latitude. Two cases were considered, the first under stable IMF $B_{z}$ negative and the latter under stable $B_{z}$ positive. These examples were chosen to coincide with radiotomography reconstructions that had mature interpretations from multi-instrument studies. The stable conditions were essential for the model in its current simulation application, where only steady convection is supported. The chosen potential patterns were therefore regarded as representative of the entire intervals of interest.

The electric potential pattern used in the model for $B_{z}$ negative was obtained from measurements made during the interval of interest, and was representative of the patterns observed throughout the interval. In this case the effects of the TOI were clearly observed in the model output in the postmagnetic midnight sector. The densities of the modelled feature were only slightly smaller than those observed, with the exception of the pass at 00:07 UT, with the differences being generally $\sim 1 \times 10^{11} \mathrm{~m}^{-3}$ or less. Both observations and model showed the trend of decreasing density with UT, attributed to ionisation recombination in winter darkness. The latitudinal location of the feature also compared well, although the model failed to reproduce the observed gradients on the walls of the enhancement, a likely consequence of the resolution of the model being lower than that of the tomography reconstruction. The model output in the study showed improvement over that obtained by Middleton et al. (2008) who used a selected library potential pattern. 


\section{UT}

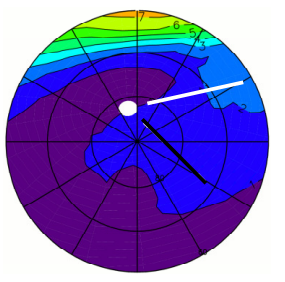

18 UT

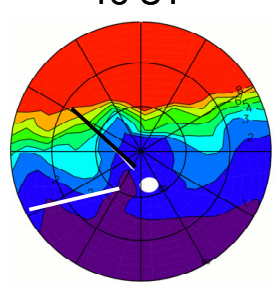

\section{Nov 2001}
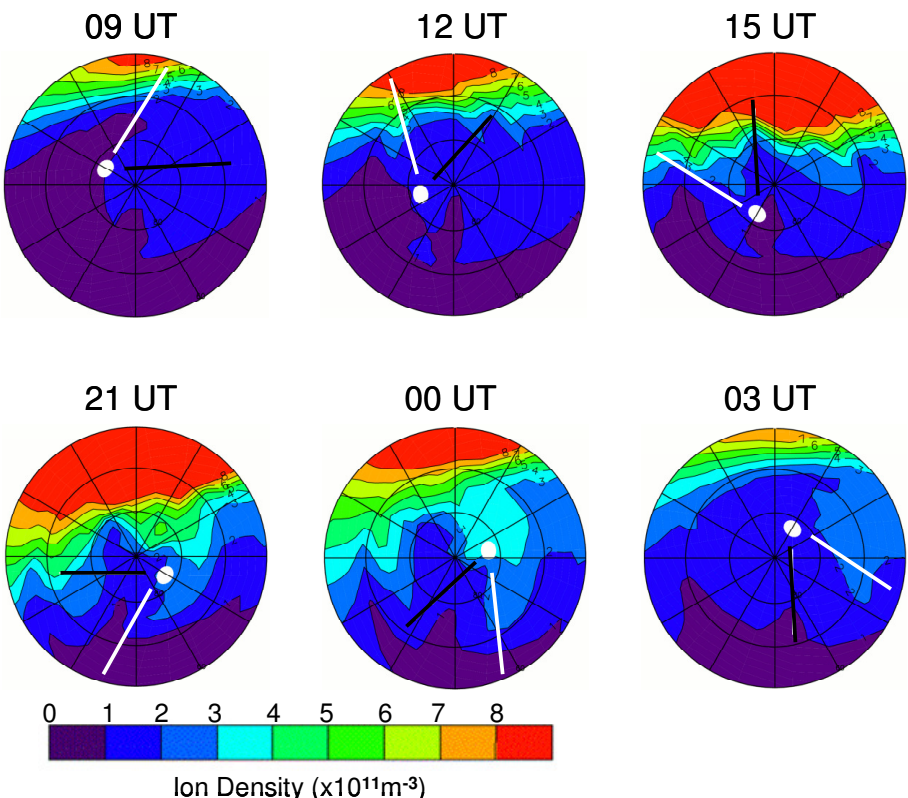

Fig. 11. Ion densities modelled by CTIP for 26 November 2001. The panels are at 3-h intervals of UT, with each panel showing the ion density distribution at an altitude of $270 \mathrm{~km}$, near the F-region ionisation peak, as a function of MLAT and MLT. The format of the panels is as for Fig. 4, with the white line showing the $18^{\circ} \mathrm{E}$ meridian near the longitude of the Scandinavian tomography chain and the black line indicating the $54^{\circ} \mathrm{W}$ meridian near the longitude of the Greenland chain.
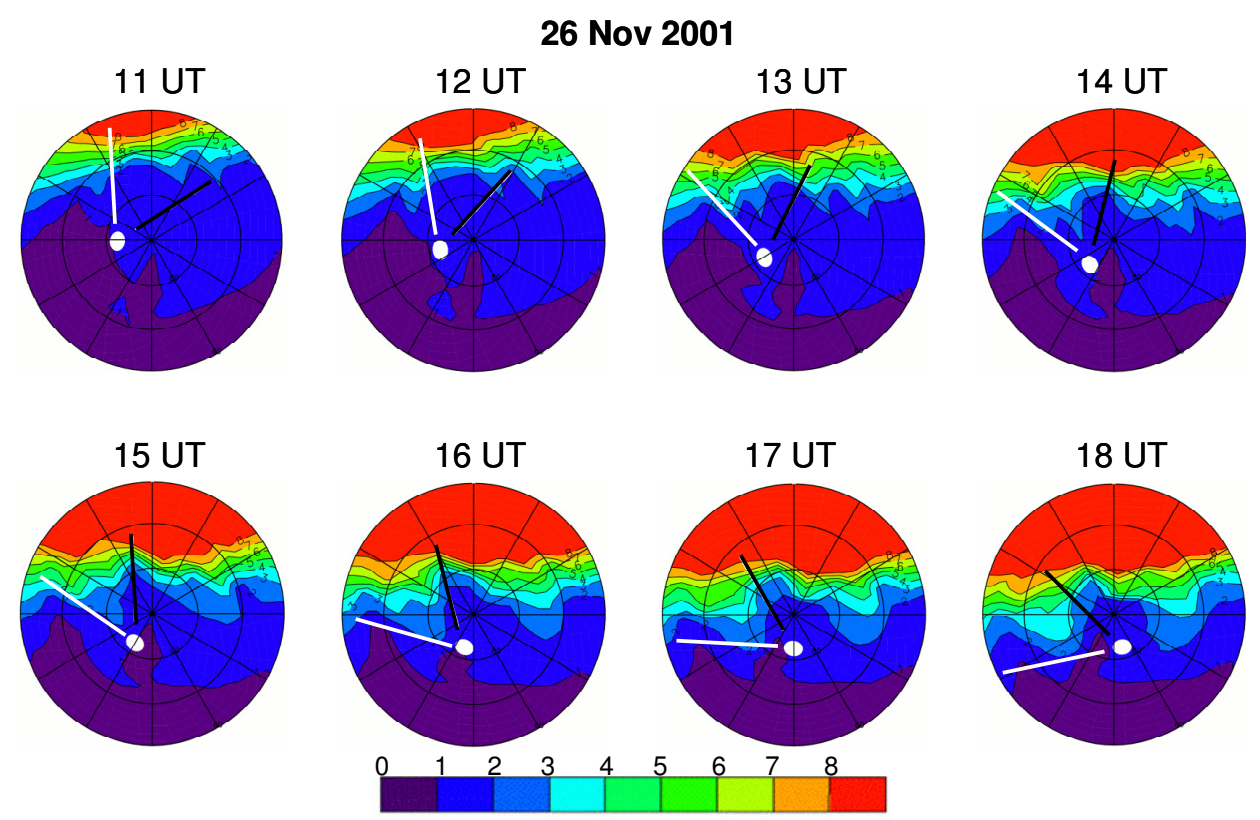

Ion Density $\left(\times 10^{11} \mathrm{~m}^{-3}\right)$

Fig. 12. Ion densities modelled by CTIP between 11:00 UT and 18:00 UT for 26 November 2001. The panels are at hourly intervals of UT, with each panel showing the ion density distribution at an altitude of $270 \mathrm{~km}$, near the F-region ionisation peak, as a function of MLAT and MLT. The format of the panels is as for Fig. 4, with the white line showing the $18^{\circ}$ E meridian near the longitude of the Scandinavian tomography chain and the black line indicating the $54^{\circ} \mathrm{W}$ meridian near the longitude of the Greenland chain. 

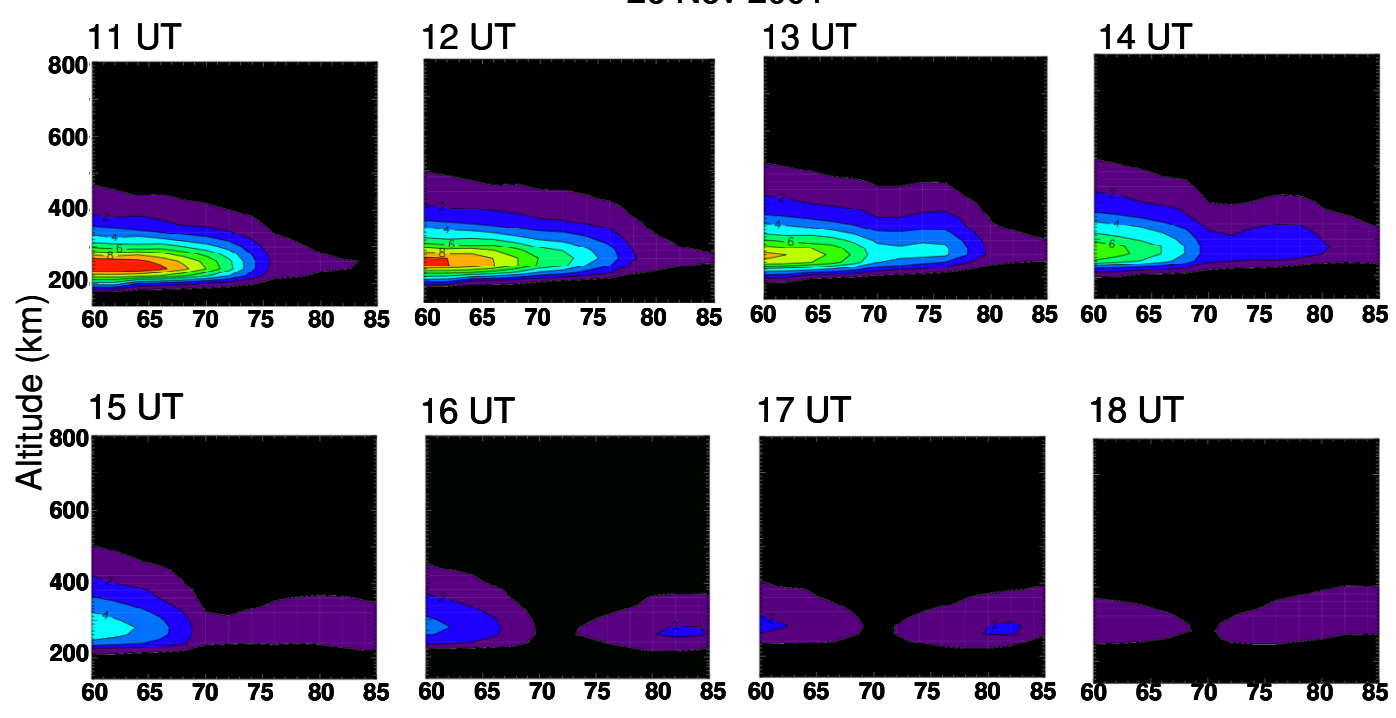

17 UT

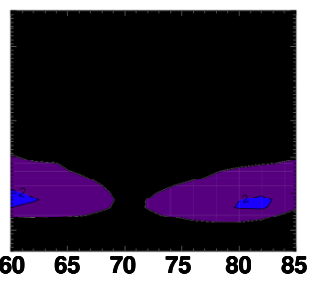

18 UT

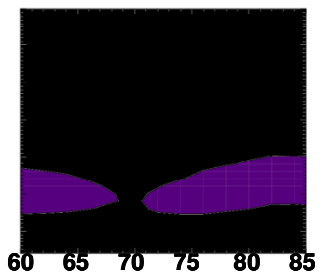

Geographic Latitude (degrees)

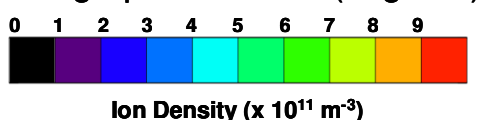

Ion Density $\left({\left.\mathbf{x ~} 10^{11} \mathrm{~m}^{-3}\right)}^{-3}\right.$

Fig. 13. CTIP modelled ion densities at hourly intervals between 11:00 UT and 18:00 UT for latitude-versus-altitude planes at the $18^{\circ} \mathrm{E}$ meridian.

There were only limited SuperDARN measurements at the time of the $B_{z}$ positive case, and an electric potential pattern from a different time period was used. IMF $B_{z}$ was also positive and stable during this interval, albeit larger in magnitude. The flow pattern was representative of that anticipated for the IMF conditions and in-keeping with the form of the DMSP horizontal drift measurements in Middleton et al. (2005). The model output yielded an ionospheric distribution broadly similar to that observed, with a tongue-ofionisation being drawn around the periphery of the polar cap. However, there were differences in the latitude of the modelled and observed tongue with the modelled location being slightly equatorward of that observed and the modelled densities being smaller, discrepancies that could have arisen because of the convection pattern not being that for the exact interval of interest. Nevertheless, it is important to note that the model in this instance was able to reproduce a TOI being drawn around the periphery of the polar cap in keeping with the processes inferred from the observations. This was not possible with the previous standard electric potential input to the model.

The results of the study pave the way for comparisons of the modelled ionosphere with radiotomography reconstructions and observations by other experimental techniques under a range of different geophysical conditions, in particular IMF orientation and magnitude, season, and solar cycle. The dependency of the spatial distribution of ionisation on the longitude of observation, attributed to the offset of the ge- ographic and geomagnetic reference systems, also requires further consideration, and future comparisons between the model and radiotomography observations in different longitude sectors have the potential to establish the complementary distributions of different regions of the globe. The morphology of plasma distribution in different sectors is not only of interest to the understanding of the physics of the density structuring, but is also of relevance to radio applications where latitudinal gradients on the walls of plasma enhancements and troughs are of concern to practical radio systems.

\section{Conclusions}

The presented investigation has focussed on the modelling of the ionospheric plasma distribution in the polar and auroral regions using the CTIP model. The new aspect has been the use of electric potentials obtained from the SuperDARN network as input. Two cases were considered, both under stable conditions of IMF $B_{z}$ negative and positive respectively, where there were radiotomography reconstructions available for comparisons. Both sets of tomography reconstructions had been the focus of previous multi-instrument studies and had mature interpretations. The modelled plasma distributions were compared with those observed by radiotomography. No attempt was made to tweak the model for better agreement with the observations. 
Good agreement was obtained between the modelled and observed densities under conditions of $B_{z}$ negative with both revealing the effect of the tongue-of-ionisation drawn from the dayside, over the pole and into the nightside. In this instance the SuperDARN electric potentials were derived from measurements made during the time of interest and the convection was representative of the flows throughout the interval. Sufficient SuperDARN measurements were not available for the time period of radiotomography observations under $B_{z}$ positive, and electric potentials for a period under similar, stable conditions were used where the flow resembled that anticipated for $B_{z}$ northward. Although the electric potential pattern did not correspond directly to the time of density observations, it is important to bear in mind that the applied pattern was a significant improvement from those available previously in the library of potential patterns. In this case a TOI drawn antisunward around the periphery of the polar cap was both modelled and observed. Both cases illustrate the potential of SuperDARN electric potential patterns to improve agreement between the CTIP model and observations.

Acknowledgements. Financial support for the project was provided by the UK Science and Technology Facilities Council under grant PP/E001157/1. The International Ionospheric Tomography Community (IITC) was an outgrowth of a workshop conducted under the Polar Aeronomy and Radio Science (PARS) program sponsored by the U.S. Office of Naval Research via a grant to the University of Alaska and subgrant 0014 to NWRA. The radio receivers of the tomography experiments of the IITC were operated by Aberystwyth University (AU), NorthWest Research Associates, Inc., (NWRA) and the Applied Research Laboratories (ARL) of the University of Texas. AU acknowledges the assistance of the University of Troms $\varnothing$ and the Norwegian Polar Institute in their tomographic measurements. The SuperDARN radar facility is funded by the National Research Programs of Australia, Canada, Finland, France, Japan, South Africa, Sweden, UK and USA. The IMF data was provided by $\mathrm{N}$. Ness and obtained from the CDAWeb. ML is supported by STFC grant PP/E000983. One author, JAS, was supported by the High Frequency Active Auroral Research Program (HAARP), Air Force Research Laboratory, Hanscom Air Force Base, Massachusetts, on Contract No. F8718-04-C-0001. ELW acknowledges receipt of a STFC postgraduate studentship.

Topical Editor M. Pinnock thanks one anonymous referee for her/his help in evaluating this paper.

\section{References}

Anderson, D. N., Buchau, J., and Heelis, R. A.: Origin of density enhancements in the winter polar cap ionosphere, Radio Sci., 23, 513-519, 1988.

Bowline, M. D., Sojka, J. J., and Schunk, R. W.: Relationship of theoretical patch climatology to polar cap patch observations, Radio Sci., 31, 635-644, 1996.

Chisham, G., Lester, M., Milan, S. E., Freeman, M. P., Bristow, W. A., Grocott, A., MacWilliams, K. A., Ruohoniemi, J. M., Yeoman, T. K., Dyson, P., Greenwald, R. A., Kikuchi, T., Pinnock, M., Rash, J., Sato, N., Sofko, G., Villain, J.-P., and Walker, A. D.
M.: A decade of the Super Dual Auroral Radar Network (SuperDARN): Scientific achievements, new techniques and future directions, Surv. Geophys., 28, 33-109, doi:10.1007/s10712-0079017-8, 2007.

Cowley, S. W. H.: Excitation of flow in the Earth's magnetosphereionosphere system: observations by incoherent scatter radar, in: Polar Cap Boundary Phenomena, edited by: Moen, J., Egeland, A., and Lockwood, M., NATO Advanced Study Institute Series, Kluwer Academic Press, Dordrecht, The Netherlands, 509, 127 140, 1998.

Crowley, G.: Critical review of ionospheric patches and blobs, URSI Review of Radio Science 1993-1996, edited by: Stone, W. R., 619-648, 1996.

Foster, J. C., Holt, J. M., and Musgrove, R. G.: Ionospheric convection associated with discrete levels of particle precipitation, Geophys. Res. Lett., 13, 656-659, 1986.

Fuller-Rowell, T. J., Rees, D., Quegan, S., Moffett, R. J., and Bailey, G. J.: Interactions between neutral thermospheric composition and the polar ionosphere using a coupled ionospherethermosphere model, J. Geophys. Res., 92, 7744-7748, 1987.

Fuller-Rowell, T. J. and Rees, D.: Derivation of a conservation equation for mean molecular weight for a two-constituent gas within a three-dimensional, time-dependent, model of the thermosphere, Planet. Space Sci., 31, 1209-1222, 1983.

Fuller-Rowell, T. J. and Rees, D.: A three-dimensional, timedependent, global model of the thermosphere, J. Atmos. Sci., 37, 2545-2567, 1980.

Greenwald, R. A., Baker, K. B., Dudeney, J. R., Pinnock, M., Jones, T. B., Thomas, E. C., Villain, J.-P., Cerisier, J.-C., Senior, C., Hanuise, C., Hunsucker, R. D., Sofko, G., Koehler, J., Nielsen, E., Pellinen, R., Walker, A. D. M., Sato, N., and Yamagishi, H.: Darn/Superdarn: A global view of the dynamics of high-latitude convection, Space Sci. Rev., 71, 761-796, 1995.

Middleton, H. R., Pryse, S. E., Wood, A. G., and Balthazor, R. L.: The role of the tongue-of-ionisation in the formation of the poleward wall of the main trough in the European post-midnight sector, J. Geophys. Res., 113(A2), A02306, doi:10.1029/2007JA012631, 2008.

Middleton, H. R., Pryse, S. E., Kersley, L., Bust, G. S., Fremouw, E. J., Secan, J. A., and Denig, W. F.: Evidence for the tongue of ionisation under northward IMF conditions, J. Geophys. Res., 110(A7), A07301, doi:10.1029/2004JA010800, 2005.

Milan, S. E., Lester, M., and Yeoman, T. K.: HF radar polar patch formation revisited: summer and winter variations in dayside plasma structuring, Ann. Geophys., 20, 487-499, 2002, http://www.ann-geophys.net/20/487/2002/.

Millward, G. H., Moffett, R. J., Quegan, S., and Fuller-Rowell, T. J.: A coupled thermosphere-ionosphere-plasmasphere model (CTIP), Solar-terrestrial energy programme (STEP) handbook of ionospheric models, edited by: Schunk, R. W., 239-279, 1996.

Pryse, S. E., Wood, A. G., Middleton, H. R., McCrea, I. W., and Lester, M.: Reconfiguration of polar-cap plasma in the magnetic midnight sector, Ann. Geophys., 24, 2201-2208, 2006, http://www.ann-geophys.net/24/2201/2006/.

Pryse, S. E., Dewis, K. L., Balthazor, R. L., Middleton, H. R., and Denton, M. H.: The dayside high-latitude trough under quiet geomagnetic conditions: Radio tomography and the CTIP model, Ann. Geophys., 23, 1199-1206, 2005, http://www.ann-geophys.net/23/1199/2005/. 
Pryse, S. E.: Radiotomography: A new experimental technique, Surv. Geophys., 24, 1-38, 2003.

Quegan, S., Bailey, G. J., Moffett, R. J., Heelis, R. A., FullerRowell, T. J., Rees, D., and Sprio, R. W.: A theoretical study of the distribution of ionisation in the high-latitude ionosphere and the plasmasphere: first results on the mid-latitude trough and the light-ion trough, J. Atmos. Terr. Phys., 44, 619-640, 1982.

Robinson, R. M., Tsunoda, R. T., and Vickrey, J. F.: Sources of Fregion ionisation enhancements in the nighttime auroral zone, J. Geophys. Res., 90, 7533-7546, 1985.

Rodger, A. S., Pinnock, M., Dudeney, J. R., Baker, K. B., and Greenwald, R. A.: A new mechanism for polar patch formation, J. Geophys. Res., 99, 6425-6436, 1994.

Ruohoniemi, J. M. and Baker, K. B.: Large-scale imaging of highlatitude convection with Super Dual Auroral radar Network HF radar observations, J. Geophys. Res., 103, 20797-20811, 1998.
Schoendorf, J., Aylward, A. D., and Moffett, R. J.: Modelling high-latitude electron densities with a coupled thermosphereionosphere model, Ann. Geophys., 14, 1391-1402, 1996, http://www.ann-geophys.net/14/1391/1996/.

Sojka, J. J., Bowline, M. D., and Schunk, R. W.: Patches in the polar ionosphere: UT and seasonal dependence, J. Geophys. Res., 99, 14959-14970, 1994.

Sojka, J. J., Bowline, M. D., Schunk, R. W., Decker, D. T., Valladares, C. E., Sheehan, R., Anderson, D. N., and Heelis, R. A.: Modelling polar-cap F-region patches using time-varying convection, Geophys. Res. Lett., 20, 1783-1786, 1993.

Sojka, J. J., Raitt, W. J., and Schunk, R. W.: A theoretical study of the high-latitude winter $\mathrm{F}$ region at solar minimum for low magnetic activity, J. Geophys. Res., 86, 609-621, 1981.

Valladares, C. E., Basu, S., Buchau, J., and Friis-Christensen, E.: Experimental evidence for the formation and entry of patches into the polar cap, Radio Sci., 29, 167-194, 1994. 